\title{
The toxicology and detoxification of Aconitum: traditional and modern views
}

\author{
Yau-Tuen Chan, Ning Wang ${ }^{*}$ and Yibin Feng ${ }^{*}$
}

\begin{abstract}
Aconitum carmichaeli Debx.-derived herbal medicine has been used for anti-inflammation and anti-arrhythmia purpose for more than two thousand years. It is processed into Chuanwu (Radix Aconiti praeparata) and Fuzi (Radix Aconiti lateralis praeparata) in Traditional Chinese Medicine, which are two useful drugs but with toxic properties. There have been patients poisoned by accidental ingestion of Aconitum plants or misuse of the herbal drug, and this is of great concern to study in-depth. In this review, we provided the traditional and contemporary practice of using Aconitum herbs as medicine, from functions, processing methods to toxicity in ethnomedicine aspects to discuss the underlying connections of traditional and modern understanding on the toxicity of Aconitum plants. We summarized the functions and toxicology of the herbal drugs are analyzed from chemical and clinical aspects, with the help of traditional and modern knowledge of medicine. The medicinal doses and lethal doses determined by researches are summarized, and the usage and processing methods are updated and reviewed in the modern view. In addition, clinical management of poisoned cases using western medicine is discussed. This review provides insights and awareness of safety when using Aconitum-derived herbal medicine, and the application of modern scientific knowledge to optimize the detoxification processes. We suggest the possibility to renew the current standard processing method from the official Pharmacopoeia all over the world.
\end{abstract}

Keywords: Aconitum, Aconitine, Toxicology, Drug processing, Detoxification

\section{Introduction}

Aconitum is a genus of herbal medicine in the Ranunculaceae family, with more than 400 species all over the world [1]. Aconitum plants, also having the names of aconite, monkshood, wolf's bane, queen of poisons, are a branch of herbal drugs in traditional Chinese Medicine [2]. Caowu, Chuanwu, Fuzi and Tianxiong are four examples of Chinese herbal drugs that are deriving from the same species Aconitum carmichaelii Debx., which is the common herb to be used nowadays [3]. The medical use of Aconitums, regardless of the raw or processed herbs, are highly cautious since its obvious toxicity. Despite the potential danger, the clinical applications of Aconitum

\footnotetext{
*Correspondence: ckwang@hku.hk; yfeng@hku.hk

School of Chinese Medicine, The University of Hong Kong, Hong Kong, China
}

species are becoming more systematic with the increasing understanding of its toxicology and methods of detoxifications.

There have been poisoned cases reported even until recent years in herbal medicines used regions, including China, Hong Kong [4], Taiwan and India [5], etc. It may sound dangerous to use these kinds of toxic drugs. However, due to the essential role of the Aconitum in many diseases, including rheumatism, joint pains [6], oedema, gastroenteritis [7], asthma, abdominal pains [8, 9], and some gynaecological disorders like irregular menstruation and dysmenorrhea, it is a very efficient herbal drug to ease pains, as a result of its effect on the neuronal cells, which will be described in detail later. It is a restricted Chinese medical drug to be used, but not prohibited in Hong Kong. Therefore, it is important to investigate indepth the effect, toxicity, risk, and treatment related original author(s) and the source, provide a link to the Creative Commons licence, and indicate if changes were made. The images or other third party material in this article are included in the article's Creative Commons licence, unless indicated otherwise in a credit line to the material. If material is not included in the article's Creative Commons licence and your intended use is not permitted by statutory regulation or exceeds the permitted use, you will need to obtain permission directly from the copyright holder. To view a copy of this licence, visit http://creativecommons.org/licenses/by/4.0/. The Creative Commons Public Domain Dedication waiver (http://creativeco mmons.org/publicdomain/zero/1.0/) applies to the data made available in this article, unless otherwise stated in a credit line to the data. 
to the toxification of the Aconitums. In this review, we retrieved literature from the PubMed database and summarized the traditional use and the recent advances in the investigation of toxicity, toxicology and processing to detoxification of Aconitums. With a clinical-oriented aspect, we also focus on the clinical symptoms and management of Aconitums intoxication in humans. The toxicokinetic information of Aconitum alkaloids is investigated by Yang et al. in the recent article [10], and that would not be covered in this review.

\section{Ethnophamracological relevance of Acontitum toxicity}

\section{The use of Aconitums in traditional medicine}

China has a long history of using Aconitum as a herbal drug. It was first recorded in Shennong's Materia Med$i c a$, the very first Chinese herbal medicinal classic dated around two thousand years ago. More detailed information, taxonomy, usage on the species Aconitum carmichaeli Debx. derivatives Chuanwu (Radix Aconiti praeparata) and Fuzi (Radix Aconiti lateralis praeparata) were illustrated in another classic "Shanghan Lun" written by the master Zhang Zhongjing in the Eastern Han Dynasty [11]. It was classified as a "lower-class" drug, and marked as "very poisonous" that must be used with extreme care. The Aconitum species were categorized as the "warm" drugs, that can power up and energize the body, dispel moisture and humidity, as well as ease pain. Fuzi was included in more than 20 herbal drug formulae [12]. The amounts of Chuanwu and Fuzi that could be prescribed to a patient were listed in the traditional materia medica. For Chuanwu, the amount should be $1.5 \sim 3 \mathrm{~g}$ (translated to Standard Unit) in formulation, while used as a single drug should not be more than $2 \mathrm{~g}$. The amount of Fuzi could be as high as $15 \mathrm{~g}$, as the toxicity of Fuzi is less toxic, especially in the processed form. In recent years, prescribing Fuzi becomes one of the most crucial schools of thought in Chinese medicine.

Apart from the physicians from the past, Aconitum herbs were also used locally as folk medicine or supplement. People from the rural villages in the Qinling Range of the Shaanxi Province in China used to cook and consume A. carmichaeli before winter [13]. They had a saying that taking the herbs will give them warmth during the winter, and also energy for everyday work. They would not cook the herb like other vegetables, but cutting the root into slices, and boiling in a soup. The soup was kept boiling to dry up and added water back several times. The whole process should last for hours to several days. They claimed very few people felt unwell after consuming Aconitum in this way.

Other than the ancient Chinese, Indian also has a long history in alternative medicine, or non-allopathic medicine $[14,15]$. There were different systems of medicinal practice including Unani, Siddha, Ayurveda, etc., but would not be discussed in detail here. They have Aconitum herbs introduced as drugs, and they also realized the toxicity of aconitine (AC). Before the usage of the herb, the Indian would boil the root of the plants with cow's urine for two days. It is then washed with water and boiled again with milk for two more days. After that, the residue will be cut and dried. They preserved the product in powdered form. The Indian used Aconitum herbs to combat fever, inflammation, emesis and diarrhoea [16]. However, toxic injured and fatal cases are reported. It is observed that boiling for a prolonged time is a rural method of processing the Aconitum herb to reduce toxicity.

\section{Traditional processing methods of Aconitum in TCM}

Paozhi is the Chinese term for processing crude herbal drugs using specific methods, that can reduce the toxicity of the drug while maximizing its effectiveness. There can be more than one method to process the same herb, that can bring about different pharmacological functions [17].

In this review, only the processing methods of Aconitum carmichaeli Debx. herb would be reviewed (Fig. 1). The raw plant Aconitum carmichaeli are commonly cultivated in the Sichuan Province, but also natively found in Russia, Japan and other East Asia region [18]. It is a perennial plant that has a purple in colour flower which could be $60-150 \mathrm{~cm}$ tall when mature completely. This plant is usually grown on a grass slope, in between bushes. The underground tuber root should be collected in early summer, from June to August, just before the flowering period. This plant could be derived into three different types of herbal drugs, namely "Shengchuanwu", "Zhichuanwu" as well as "Fuzi" $[19,20]$, according to the Pharmacopoeia of the People's Republic of China, 2020.

"Shengchuanwu" is derived from the mother root of the radix plant by drying, "Zhichuanwu" is the processed form of "Shengchuanwu", while "Fuzi" is processed from the daughter root of the same plant. "Shengchuanwu" is produced rather simple by drying under the sun after the lateral roots, sand and soil are removed. When tasted on the tongue, one should feel slight numbness. From the raw "Shengchuanwu", the large root part is soaked into water, then boiled for $4-6 \mathrm{~h}$ or steamed for $6-8 \mathrm{~h}$, and then sliced and dried under the sun. This processed form of Chuanwu is the "Zhichuanwu. On the other hand, "Fuzi" and its derivatives are much more complicated. "Fuzi" means attached offspring in Chinese, which is the daughter root of the radix. Fuzi itself are poisonous as well, therefore it must be processed before use. The crude Fuzi, which is also called "Nifuzi" or "Zhifuzi", is selected lateral roots with soil and sands removed. It could be 


\title{
Aconitum
}

(Chuanwu, Caowu, Fuzi, Tianxiong)

\section{Toxic compounds $\quad$ Cardio- and neuro- toxicity}
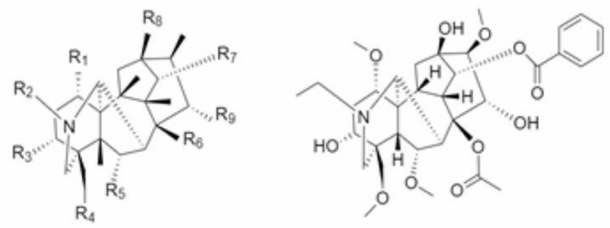
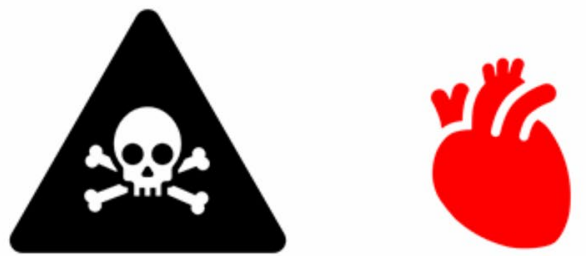

\section{Herb-herb combinations}

\section{Ginseng Gancao Ganjiang Dahuang}

- Reduce toxic compounds

- Enhance drug therapeutic actions

- Different ratios have different effects

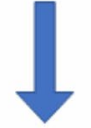

Processing methods

- Boiling to reduce DDAs

- Paozhi: saline, sun-dry, heat

- Steaming, autoclaving

\section{Quality Control}

\author{
Moisture\%, Ash\%, MDAs, DDAs \\ - UPLC - UPLC-MS/MS - LC-ESI-MS/MS
}

Fig. 1 Graphical abstract of the Aconitum toxicology and detoxification

further processed into five different herbal drugs. "Yanfuzi" is made by soaking Nifuzi into saline with repetitive drying until it is hardened and the surface is coated with salt crystals. "Heishunpian" is another type of processed Fuzi, which in addition to soaking in saline, it is also boiled and stained to become dark, or black in colour. They should be dried under the sun and will have no numbness feels when tasted. The third one is "Baifupian", which are produced using the root with the bark skin removed. They are boiled in saline as well and dried under the sun. To enhance its white colour, sometimes the product will be steamed with sulphur. The fourth one is "Danfupian", which is made by washing the Yanfuzi in water until the salt is complete removed, and boiled with Licorice and black beans. The final one is "Paofupian", which is Fuzi processed by deep frying in hot sands until plump and slightly coloured.

There are some other Aconitum species also used for herbal drug, including Aconitum kusnezoffii Radix (Caowu), Aconitum kusnezoffii Radix cocta. (Zhicaowu), Aconitum kusnezoffi Folium (Caowuye), Aconitum coreanum Rapaics (Guanbaifu) and Aconitum pendulum Busch (Xueshangyizhihao).

\section{Medicinal effects of Aconitum species}

In TCM practice, herbal drugs are given to patients in a compound formulation, instead of a single drug or compound. According to the TCM theory, most of diseases are induced by an imbalance of the inner "yin-yang" in the human body. Different diseases are the results of disturbance of different organ system, and so prescriptions are usually given in a formulation. The complex compounds present in the formulation could help the body regain its original optimal state.

\section{Effects in the cardiac system}

In the school of Chinese Medicine, "huoshen", which prefers to use Aconitum a lot in many decoctions, this herb is important to enhance cardiopulmonary functions. Other than the toxic effect mentioned previously, as a drug, the Aconitum herbs also bring beneficial effects to the cardiac system [21]. As recorded in the Chinese Classics, the Fuzi 
has the effect of "warming up and energize" bodies. This could be described in modern medicine using the cardiotonic actin [22]. The major energy source of the cardiac muscle is adenosine triphosphate, which is produced mainly from cellular respiration in the mitochondria, and a minority of them from glycolysis [23]. Adenosine monophosphate-activated protein kinase (AMPK) is an enzyme that regulates cellular energy homeostasis by activating glycolytic and fatty acid metabolism [24]. Deng et al. showed that Benzoylaconine (BAC) could promote mitochondria accumulation and ATP production in a dose-dependent manner. BAC could activate oxidative phosphorylation related protein expression in various organs including the heart, and increase oxygen consumption. Other compounds are also involved, including napelline, lappaconitine (LA) and 6-benzoylheteratisine [25]. LA, and its metabolite $N$-deacetyllappaconitine (DLA), showed antiarrhythmic actions while having a lower toxicity. Mice have 500 to 100 times higher tolerance in terms of causing arrhythmia when comparing LA and DLA to AC [26].

Shenfu Tang, Shenfu San, or Shenfu Injection (SFI), are a series of herbal drug formulas that involve the usage of Fuzi, as well as Ginseng (Radix ginseng) [27]. Both of these drugs have very effective power in energizing severe patients and help recover from chronic illness. An example was to be applied to the treatment of anaemia in patients with lung cancer. After 14 days of intravenous injection of SFI, the performance status of the patients was generally improved when compared with the control group, measured using the Karnofsky score. In the meantime, the anaemia situation and immune level were also improved [28]. It was also reported that SFI $(\sim 10 \mathrm{mg} / 24$ h, i.v. $)$ had positive effects in the recovery of patients suffering from myocardial infarction [29]. Sixty myocardial infarction patients were given the cardiogenic shock and treated with an intra-aortic balloon pump, and then half of them were given SFI. The result showed that SFI significantly shortens the recovery time of the patients, by reducing the inflammation response.

\section{Analgesic effects}

In TCM, processed Aconitum or Fuzi are used as an analgesic agent when treating diseases like rheumatoid arthritis [30]. It is shown that the alkaloids, other than the toxic ones, in the plant have a different extent of analgesic activity [31-33]. Researches indicated that $\mathrm{AC}$, as well as 3-acetylaconitine and hypaconitine (HA), were the highest affinity to the sodium channel. When AC molecules bind to the sodium channel, at site II, the ionic flow through the channel will decrease. In that case, the sodium ion influx is affected, which changes the selectivity of the channel. The opening of the sodium channel is prolonged, which results in an extension, or even permanent depolarization of neurons. This corresponds to blocking of synapse signally passage, and thus account for the antinociceptive and analgesic effect of AC [34]. This was found in the hippocampus, where neuronal conduction was inhibited. Nevertheless, these three compounds are also having high toxicity. The ratio of $\mathrm{ED}_{30}$ to analgesia is similar to the $\mathrm{LD}_{50}$, only from two (3-acetylaconitine) to six (AC) times. Therefore, they are not suitable to be considered as druggable analgesics. Thus, lappaconitine (LA) shines as a better candidate for analgesics, due to its low toxicity $[35,36]$. LA has more or less level of analgesic activity, when comparing to morphine, in different tests on mice and rats [37, 38].

The anti-inflammation action also assists in the analgesic effect in the treatment of some diseases, for example, Fuzi alkaloids can mitigate the symptoms of patients with allergic rhinitis [39]. Sneezing, nasal secretions and nasal scratching were alleviated in the study, where the inflammation of nasal mucosal cells was improved through the decrease of histamine content. The use of Fuzi was proven to be safe also in clinical application.

Chuanwu also has analgesic and anti-inflammatory effect in oedema. In a mice model of carrageenaninduced paw oedema, water extract of Chuanwu at $60 \mathrm{mg} / \mathrm{kg}$ showed efficient inhibition in oedema [40]. It was believed that mesaconitine (MA), which presented as the highest concentration alkaloids in the sample, responsible for the antinociceptive and anti-inflammatory effects.

\section{Effects on gynaecological disorders}

In TCM practice, Fuzi has been used for regulating or balancing the patients' endocrine system [9]. It could help alleviate many gynaecological symptoms, including abdominal cramps, painful menstruation, irregular menstruation [41], and other gynaecological disorders like climacteric disorder. However, physicians should avoid administering Aconitum drugs to pregnant women, as AC has high toxicity to embryo development [42].

\section{Poisoned symptoms and toxicology}

\section{Chemical aspects of the toxicology of Aconitum}

The active compounds found in the Aconitum species are mainly alkaloids, with three major groups namely monoester diterpene alkaloids (MDAs), diester diterpene alkaloids (DDAs) and lipoalkaloids. The most important active constituents are $\mathrm{C}_{19}$-diterpenoid alkaloids and C20-diterpenoid alkaloids. The compounds are served as a double-edged sword because they are both toxic while having medicinal beneficial effects.

The major toxic compounds are the DDAs including $\mathrm{AC}, \mathrm{MA}$, and HA. DDAs are a type of diterpene 
alkaloids, which shares a $\mathrm{C}_{19}$ norditerpenoid skeleton [43, 44]. The skeleton chemical structure is shown in Fig. 2a. The aconites all having the same skeleton, but with different side chains as functional constituents substituted at different sites. Wherever an acetyl group and a benzoyl ester group are attached to $\mathrm{C}-8\left(\mathrm{R}_{6}\right.$ in Fig. $\left.2 \mathrm{a}\right)$ and $\mathrm{C}-14$ $\left(R_{7}\right)$, the alkaloids would be toxic. AC is a typical example (Fig. 2b). They are the most toxic compounds among all the alkaloids found from the herb. MDA, including benzoylaconine (BAC), benzoylmesaconine (BMA) and benzoylhypaconine (BHA), in comparison, has a lower toxicity level and thus the medicinal value is higher. There is no acetyl substituent in the C-8 $\left(\mathrm{R}_{6}\right)$ in MDAs, which is usually replaced by a hydroxyl group (e.g. BAC, BMA, BHA) $[45,46]$. Alkaloids consist of different structures and functional groups will exhibit different activity in the body. From which, compounds with cardiac activities are generalized by Jian et al. in 2012 [47]. For $\mathrm{C}_{19}$-diterpenoid alkaloids without ester groups, an alphahydroxyl group at C-15 $\left(\mathrm{R}_{9}\right)$, a hydroxyl group at C-8 $\left(\mathrm{R}_{6}\right)$, an alpha-methoxyl or hydroxyl group at $\mathrm{C}-1\left(\mathrm{R}_{1}\right)$ and an amine or $\mathrm{N}$-methyl group in ring A could bring possible cardiac activities.

AC is extremely toxic to human, which will cause death with just $2 \mathrm{mg}$, while the toxic dose is only one-tenth of that [48]. HA, however, is the most potent toxic compound, which exists in a relatively lower proportion. The diterpene alkaloids have either a hydroxyl, acetoxyl or fatty acid acyl group as functional groups, while the effect of many of the compounds is not yet been investigated (Table 1).

\section{Clinical symptoms of Aconitum poisoning}

Typical symptoms of patients poisoned by aconite derivatives include nausea, vomiting, palpitation, arrhythmia [49], muscle dysfunction, perioral paranesthesia, respiratory tract infection and pain, breathing difficulties, convulsion, gastrointestinal upset $[50,51]$, and even shock and coma [52,53]. It is of course lethal in serious cases, which are usually the result of ventricular arrhythmia. There is no direct antidote to aconitine poisoning, only vital supportive measures could be provided to alleviate the situation.

\section{Toxicology of Aconitum}

The toxic diester diterpene alkaloids (DDAs) found in Aconitum are well known to affect mainly cardiac function as well as the central nervous system. The DDAs, especially $\mathrm{AC}$, inhibit the inactivation of the voltagedependent sodium channel by the substitution into a binding site $[44,54]$. The binding site is located on the alpha-subunit of the sodium channel protein, which is the specific neurotoxin binding site 2 . The sodium channel is thus paralyzed, and the ionic difference, so as the action potential cannot be built up. This leads to the disruption of neurotransmitter release, and thus the neural signal transmitting pathway is disturbed [55]. The nervous system, as well as cardiac and muscular tissue, is observed to be affected mostly and fatally. The toxicity level of some of the compounds isolated from the herbs is listed in Table 2.

Interestingly, aconitine becomes a well-known activator of the sodium channel, and is used to be an experimental means to study the function of the sodium channel in the past decades [56].

\section{Toxicology in the cardiac system}

Aconite poisoning could be fatal because it affects cardiac function in the way of arrhythmia [57]. Observed symptoms of cardiovascular toxicity include hypotension, chest pain, arrhythmias, palpitation and sinus tachycardia. Due to the effect of DDAs on the sodium channels, their openings are prolonged or disrupted. The calcium and sodium ion exchange through the membrane of the myocardium makes the signalling depolarization and repolarization delayed, which causes arrhythmia. The (a)

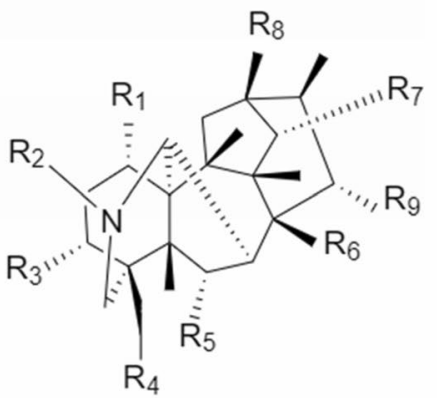

(b)

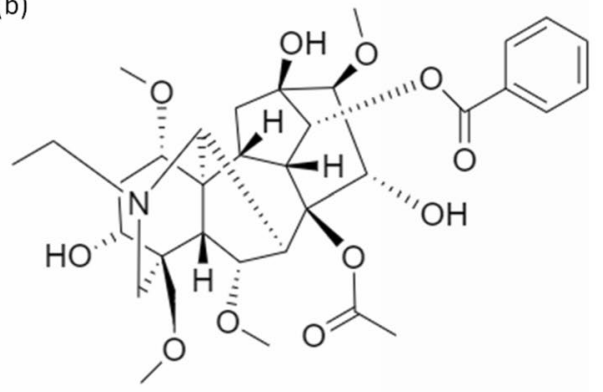

Fig. 2 Toxic compounds in Aconitum. a General chemical skeleton of DDAs. b Chemical skeleton of Aconitine 
Table 1 Effective dosages of Aconitum herbal extract and compounds

\begin{tabular}{|c|c|c|c|c|}
\hline Effect & Herb/Compound & Species & Dose & Ref \\
\hline \multicolumn{5}{|c|}{ Cardiotonic Effect } \\
\hline & Aconitine & Mouse & $5.69 \sim 8.49 \mathrm{ug} / \mathrm{kg}$ & [119] \\
\hline & Hypaconitine & Rat & $250 \mathrm{ng} / \mathrm{mL}$ & [120] \\
\hline & Higenamine & Rat & $5-10 \mathrm{mg} / \mathrm{kg}$ & [121] \\
\hline \multicolumn{5}{|c|}{ Arrhythmic Effect } \\
\hline & Aconitine & Cat & 20-40ug/kg & {$[58]$} \\
\hline & Aconitine & Rat & $1.46 \mathrm{mg} / \mathrm{kg}$ & [122] \\
\hline \multicolumn{5}{|c|}{ Anti-arrhythmic Effect } \\
\hline & Hypaconitine & Rat & $0.5 \mathrm{mg} / \mathrm{kg}$ & [123] \\
\hline & Lappaconitine & Mouse & $1.2-3.8 \mathrm{mg} / \mathrm{kg}$ & [124] \\
\hline \multicolumn{5}{|c|}{ Anti-inflammatory Effect } \\
\hline & Aconitine & Human & $\sim 10 \mathrm{mg} / 24 \mathrm{~h}$, i.v & {$[29]$} \\
\hline & Mesaconitine & Mouse & $0.2-0.5$ mg/kg p.o & {$[51]$} \\
\hline & 3-acetylaconitine & Mouse & $0.18-0.3 \mathrm{mg} / \mathrm{kg}$ & [125] \\
\hline & Lappaconitine & Mouse & 6-8 mg/kg p.o & [126] \\
\hline \multicolumn{5}{|c|}{ Analgesic Effect } \\
\hline & Aconitine & Mouse & $25 \mathrm{ug} / \mathrm{kg}$ & [127] \\
\hline & Aconitine & Mouse & 60 ug/kg & [128] \\
\hline & Mesaconitine & Mouse & $39 \mathrm{ug} / \mathrm{kg}$ & [128] \\
\hline & Hypaconitine & Mouse & $10 \mathrm{ug} / \mathrm{kg}$ & [128] \\
\hline & Pyrojesaconitine & Mouse & $78 \mathrm{ug} / \mathrm{kg}$ & [128] \\
\hline \multicolumn{5}{|c|}{ Antinociceptive Effect } \\
\hline & Aconitine & Mouse & $0.028 \mathrm{mg} / \mathrm{kg}$ & {$[34]$} \\
\hline & Mesaconitine & Mouse & $0.025 \mathrm{mg} / \mathrm{kg}$ & [129] \\
\hline & 3-acetylaconitine & Mouse & $0.097 \mathrm{mg} / \mathrm{kg}$ & {$[34]$} \\
\hline & Lappaconitine & Mouse & $2.7 \mathrm{mg} / \mathrm{kg}$ & {$[34]$} \\
\hline \multicolumn{5}{|c|}{ Hypoglycemic effect } \\
\hline & Aconitan & Mouse & 100 mg/kg & [127] \\
\hline \multicolumn{5}{|c|}{ Anti-oedema Effect } \\
\hline & A. Carmichaeli & Mouse & $60 \mathrm{mg} / \mathrm{kg}$ & {$[40]$} \\
\hline \multicolumn{5}{|c|}{ Anti-tumor Effect } \\
\hline & Fuzi extract & Mouse & 360 mg/kg & [130] \\
\hline & Aconitum-derived alkaloids & $\begin{array}{l}\text { A172, A549, Hela } \\
\text { cell lines }\end{array}$ & $1 \mathrm{ug} / \mathrm{mL}$ & [131] \\
\hline & & Raji cell line & $3 u g / m L$ & [131] \\
\hline
\end{tabular}

signals could not be transmitted through the vagus nerve normally, as long as the acetylcholine level could not be controlled at will [58]. The nerves in the cardiac system are affected by prolonging excitation, and thus arrhythmia occurs. Hypotension and bradycardia will occur as a result $[59,60]$. Furthermore, the ventromedial nucleus in the hypothalamus could be activated by $\mathrm{AC}$, which will lead to hypotension and bradycardic action [61, 62]. It is also responsible for the slowing down of the circulatory system $[63,64]$.

$\mathrm{AC}$ is sometimes used as an induction agent to arrhythmias in the study of the effect of antiarrhythmic drugs.
With different well-studied dosage, AC can create ectopic, tachycardia, fibrillation, torsades de pointes, or even death [65].

Noticeably, the above mentioned toxic effects are majorly caused by AC, MA, and HA. Different alkaloids found from the Aconitum have the opposite effect, which shows low toxicity but a high medicinal value (will be discussed in the following session).

\section{Toxicology in the neural system}

The neural system is affected in a similar way as illustrated above $[66,67]$. The neural transmitting pathway is 
Table 2 Toxic dose and $\mathrm{LD}_{50}$ of the herbs and compounds in Aconitums

\begin{tabular}{|c|c|c|c|c|c|c|}
\hline Herb/Compound & Species & p.o & S.c & i.p & i.v & Ref \\
\hline Raw Chuanwu & Mouse & $18,000 \mathrm{mg} / \mathrm{kg}$ & & & & [127] \\
\hline \multirow[t]{7}{*}{ Aconitine } & Mouse & $1.8 \mathrm{mg} / \mathrm{kg}$ & $0.24-0.31 \mathrm{mg} / \mathrm{kg}$ & $0.28-0.34 \mathrm{mg} / \mathrm{kg}$ & $0.12 \mathrm{mg} / \mathrm{kg}$ & [69] \\
\hline & Mouse & & $0.55 \mathrm{mg} / \mathrm{kg}$ & & & [128] \\
\hline & Rat & & & & $0.102 \mathrm{mg} / \mathrm{kg}$ & [127] \\
\hline & Rat & & & & $0.112 \mathrm{mg} / \mathrm{kg}$ & [103] \\
\hline & Cat & & & & $0.07-0.13 \mathrm{mg} / \mathrm{kg}$ & \\
\hline & Dog & & & & $0.5 \mathrm{mg} / \mathrm{kg}$ & \\
\hline & Human & $2-5 \mathrm{mg}$ & & & & [127] \\
\hline \multirow[t]{4}{*}{ Mesaconitine } & Mouse & $1.9 \mathrm{mg} / \mathrm{kg}$ & $0.19-0.22 \mathrm{mg} / \mathrm{kg}$ & $0.20-0.23 \mathrm{mg} / \mathrm{kg}$ & $0.10 \mathrm{mg} / \mathrm{kg}$ & {$[69]$} \\
\hline & Mouse & & $0.25 \mathrm{mg} / \mathrm{kg}$ & & & [128] \\
\hline & Mouse & & & & $0.068 \mathrm{mg} / \mathrm{kg}$ & [129] \\
\hline & Rat & & & & $0.158 \mathrm{mg} / \mathrm{kg}$ & [103] \\
\hline \multirow[t]{3}{*}{ Hypaconitine } & Mouse & $5.8 \mathrm{mg} / \mathrm{kg}$ & $1.1-1.3 \mathrm{mg} / \mathrm{kg}$ & $1.0-1.2 \mathrm{mg} / \mathrm{kg}$ & $0.47 \mathrm{mg} / \mathrm{kg}$ & {$[69]$} \\
\hline & Mouse & & 1.9 mg/kg & & & [128] \\
\hline & Rat & & & & $0.291 \mathrm{mg} / \mathrm{kg}$ & [103] \\
\hline \multirow[t]{2}{*}{ Benzoylaconitine } & Mouse & & & 70 mg/kg & $23 \mathrm{mg} / \mathrm{kg}$ & {$[69]$} \\
\hline & Rat & & & & $>20.2 \mathrm{mg} / \mathrm{kg}$ & [103] \\
\hline \multirow[t]{2}{*}{ Benzoylmesaconine } & Mouse & 810 mg/kg & $230 \mathrm{mg} / \mathrm{kg}$ & $240 \mathrm{mg} / \mathrm{kg}$ & $21 \mathrm{mg} / \mathrm{kg}$ & [69] \\
\hline & Rat & & & & $>18.7 \mathrm{mg} / \mathrm{kg}$ & [103] \\
\hline \multirow[t]{2}{*}{ Benzoylhypaconine } & Mouse & 830 mg/kg & 130 mg/kg & $120 \mathrm{mg} / \mathrm{kg}$ & $23 \mathrm{mg} / \mathrm{kg}$ & {$[69]$} \\
\hline & Rat & & & & $>20.4 \mathrm{mg} / \mathrm{kg}$ & [103] \\
\hline Lappaconitine & Mouse & & & & $5.9 \sim 11.5 \mathrm{mg} / \mathrm{kg}$ & [124] \\
\hline Jesaconitine & Mouse & & $0.23 \mathrm{mg} / \mathrm{kg}$ & & & [128] \\
\hline Songorine & Mouse & & & & 106 mg/kg & [129] \\
\hline Heteratisine & Mouse & & & & 147 mg/kg & [129] \\
\hline Napelline & Mouse & & & & $>147 \mathrm{mg} / \mathrm{kg}$ & [129] \\
\hline
\end{tabular}

disrupted by the AC poisoning, that the neuronal signal cannot normally pass through the synapse. This brings limbs abnormal controls or even paralysis. The DDAs will also cause strong contractions which can result in diarrhoea and abdominal pain $[68,69]$. The toxin could also bring damage to the central nervous system, which could lead to temporary or long-term disorder in the brain. In serious case, this can bring shock and coma.

\section{Clinical aspects of the toxicology of Aconitum}

Aconite poisoning has been a problem in the past decades, especially from the ingestion of the Aconitum plant. There were more than 41 poisoned cases reported in Hong Kong from 2012 to 2017, and at least 53 patients died because of Aconite poisoning in China [10]. The toxic level of the wild herb is much higher and fatal than the processed herbal drug, therefore the cases in the past were usually very serious, causing deaths $[57,70]$. Patients admitted to the hospital suspected of being poisoned by Aconitum plants, would show those characteristic symptoms mentioned previously, for example, nausea, vomiting, numbness, hypotension, and extra-systoles or arrhythmia [71, 72]. They would have to be monitored carefully in the intensive care unit with ECG 24-h. In serious case, the patient could result in tetraplegia [73]. Most patients who died of aconite poisoning were due to the collapsed cardiac function, in those cases, the heart beating actions were disrupted irregularly or slowed down [52, 74, 75]. However, with suitable, accurate and on-time treatment, patients who suffered from aconite poisoning could usually be rescued and survived, with or without some consequences [76-78].

\section{Detoxification of Aconitum in traditional and modern ways \\ Detoxification by herbal-herbal combinations}

Traditional Chinese medicine is particular about syndrome differentiation, and the prescriptions have nearly always more than one drug. The multiple drugs can not only alleviate different symptoms of the patients but also help retaining balance back. Moreover, the drug-drug interaction makes the whole formulation suitable for a single patient personally. Some drugs may be too "hot" to use on their own and should be balanced with some 
"cool" adjuvants. Picking compatible drugs can not only increase the drug efficacy but also reduce the side effects or even toxicity of the formulation. Fuzi, for example, is involved in some common prescription formula, including Sini Tang (Gancao, ginger, Fuzi), as well as Zhenwu Tang (Fuzi, ginger, Chinese peony (Paeonia lactiflora), etc.).

\section{Ginseng}

Ginseng (Panax notoginseng) has the best combination effect with Aconitum, in terms of detoxification and enhancing drug action. In vitro experiment has shown that Ginseng could reduce the metabolism of DDAs through inhibition of CYP3A4 expression and activity [79]. In a rat model, Ginseng could slow down the metabolisms of DDAs from Fuzi when given orally [80]. Ginseng combines with Fuzi could increase SOD activity and reduce malondialdehyde (MDA), nitrogen oxide and lactate dehydrogenase, which could enhance cardiac cell viability [81]. Through modulating the action of CYP2J3, CYP4A3, and CYP4F11, ginseng could reduce the toxicity of Fuzi and $A C$ to the heart and cardiac cells [82]. When combines with Fuzi, Ginseng could reduce the $\mathrm{LD}_{50}$ more than Licorice [83].

\section{Gancao}

Gancao (Radix glycyrrhiza sp.), also known as liquorice, is another herb that has been used with the combination of Aconitum for hundreds of years. Liquorice extract could induce the function of CYP3A4 and CYP2B6, which can increase the efflux of AC out of the cells via P-glycoprotein [84]. Glycyrrhizin and glycyrrhetinic acid, compounds extracted from gancao, has a potent antioxidant effect, which could reduce the cardiac-toxic lipid peroxidation reaction by free radical scavenging [85]. Glycyrrhetinic acid could enhance the anti-apoptotic protein $\mathrm{Bcl}-2$ expression, and reduce pro-apoptotic and pro-inflammatory cytokines such as Fas, Bax, TNF- $\alpha$ and IL-1 $\beta$, which results in cardiac protection [86]. The combination of gancao with Fuzi reduce inflammation and ventricular remodelling while enhancing survival in the mice model via TLR4/NF-kB pathway [87].

\section{Ganjiang (Dried ginger)}

Ganjiang (Zingiberis rhizoma) combined with Fuzi possess a beneficial therapeutic effect against heart failure by increasing mitochondrial biogenesis via Sirt1, PGC-1 $\alpha$ and NRF1 [88]. Ganjiang in combined with Fuzi, has a better cardiac promotion effect than Fuzi alone, by reducing $\mathrm{H}_{2} \mathrm{O}_{2}$ damage and MDA level, while increasing intracellular SOD [89]. The therapeutic effect on heart failure has risen, hemodynamics is enhanced, abnormal activation of neuroendocrine is inhibited [90].

\section{Dahuang}

Dahuang (Rhei Radix et Rhizoma) significantly reduced the DDA levels when combined with Fuzi and its derivatives [91]. The side effects of arrhythmia by Fuzi such as ventricular premature beats and ventricular tachycardia were alleviated in a dose-dependent manner by Dahuang. The effect is increased with the ratio of Dahuang to Fuzi increases, and the level of toxic alkaloids is reduced [92].

Apart from the above four herbs, Fangfeng (Saposhnikoviae radix), Huangqi (Astragali radix), Yuanzhi (Polygalae radix), Baishao (Paeoniae radix alba) also shown increase the $\mathrm{LD}_{50}$ and $\mathrm{TD}_{50}$ to different extents, when combined with Fuzi.

\section{Herbs incompatible with Aconitum}

In addition to the enhancement of drug effect with reduced toxicity, some herbs are incompatible with Aconitum. In TCM, eighteen herbs that are incompatible with each other were arranged in rhythm named " 18 incompatible medicaments". In which, Beimu (Fritillariae cirrhosae bulbus), Gualou (Trichosanthis fructus), Banxia (Pinelliae rhizome), Bailian (Ampelopsis radix), Baiji (Bletillae rhizome) were regarded to be incompatible with Aconitum. These five herbal drugs were not toxic by themselves. Analysis showed that the cardiotoxicity of Heishunpian increases when combined with the five drugs above [93].

\section{Monitoring toxicity level and quality control}

It is found that the herb-herb interaction of Aconitum containing formulation could result in significantly different pharmacokinetic fate in vivo [94]. This explained why TCM prescriptions usually involve a combination of different drugs and having specific predesigned combinations of drugs that are listed. For example, the use of Mahuang and Fuzi together could result in a lower alkaloids plasma concentration, but not BAC which is the active compound, when comparing to the use of either one single drug extract [95]. Therefore it is safer and more efficient to use more than one drugs in a specific combination. However, it is worth mentioning that the elimination value and time increased as accumulation may occur during continuous drug intake. It is essential to monitor the patient's situation before prescribing long term usage of herbal medicine.

Research demonstrated the role of P-glycoprotein (P-gp) which is encoded by the gene Mdr1 in the toxicology of AC [96]. From the experiment, the group of $M d r 1 a^{-1-}$ mice showed higher analgesic and toxic effect compared to the normal mice. The level of brain and heart damage, measured by $\mathrm{s} 100-\mathrm{B}$ protein and creatine kinase level, were significantly higher. The histopathological examination also agreed with the result, which the 
half-life of AC in the knock-down mice was dramatically higher. It is believed that P-gp is involved and responsible for the efflux of AC [97].

Due to the high toxicity level of the Aconitums, it is very crucial to have a well-developed and monitored method and system to check the quality of the herbal drugs. The method should cover both qualitative and quantitative aspects well, and help correctly processed and detoxify the medicine [98]. Liquid chromatography is one of the "golden" standards in TCM quality check, and it is again useful in the management of Aconitum derived drugs [99]. According to the Pharmacopoeia of the People's Republic of China, moisture content should be less than $15 \%$. By the means of HPLC using isopropanol-ethyl acetate as the solvent, the amount of DDAs should be determined no more than $0.020 \%$ in the processed Fuzi, and the amount of MDAs should be at least $0.010 \%$. For processed Chuanwu, the amount of DDAs should be no more than $0.040 \%$, while MDAs at the range of $0.070 \sim 0.15 \%$ [19].

\section{Detoxification by processing}

The toxicity of the drug is greatly reduced even after simple boiling. The amount of AC found in the herbs were lowered after boiling from $10 \mathrm{~min}$ to $2 \mathrm{~h}$, with an increasing level of detoxification by the lengthen of time [30, $100,101]$. The process involves mainly the hydrolysis of the DDAs into less toxic monoesters. After $2 \mathrm{~h}$ of boiling, the Baifupian showed no toxicity to the experimental mice at all, while in the 30 and 60 min group there were measured $L_{50}$ values. By using HPLC, no $A C$ and very few MA and HA were detected in the 2-h boiling sample. The absence of change in total alkaloid amount found in different boiling time suggested that the toxic compounds were transformed into less toxic derivatives through processing. The experiment also showed that there is no significant difference in the treatment efficacy in different boiling time, suggesting boiling can enhance the safety of consuming the drug while keeping its effect.

Different methods are having different advantages and disadvantages. Boiling is the easiest, but many useful chemicals will be lost by dissolving in water [102]. Cooking or baking could preserve most of the active ingredients, which at least affecting the pharmacological functions. With the advancement of technology, the methods of processing are being re-investigated. Although having very low to undetectable level of DDAs in the Paofuzhi samples prepared by method recorded in the Pharmacopoeia 2015, the level of MDAs was found to be lower than that of raw Fuzi [103, 104]. This is a sacrifice of the function by reducing the toxicity.

A study published recently analyzed the efficacy of detoxication and enhancement of medical effects by different processing methods, Shengfuzi, Paofuzi, and four methods inspired by master Zhang Zhongjing, including traditional dry-baked, modern baked, stirfried, and sand-burnt [104]. The four methods were prepared from crude Fuzi (Shengfuzi), in order to imitate the prescription ideas provided by Zhang. The results showed that the "Zhifuzi" produced by the four novel methods had a detectable low and safe amount of DDAs, while dramatically higher amount (three to four times) of MDAs were present. Another study in 2013 had similar results [103]. It suggested that the toxicity level of the processed Fuzi have no differences in the steaming or stir-fried herbs with or without saline. Using both methods, the DDAs amount could be greatly reduced by forty to eighty times at the safety level. The difference comes in the functional MDAs part, in which the amounts of MDAs increase were as much as five times in the nonsaline-treated Fuzi, compared to the insignificant difference in the saline-treated Fuzi, as the traditional method. MDAs have a much lower toxicity level, but similar level of efficacy. It was also suggested in the article, that the MDA/DDA ratio should be considered in the quality control of processing Aconitums.

And finally, steaming, or autoclaving is the newest technique to detoxify the Aconitum. The crude herbs are steamed at $127{ }^{\circ} \mathrm{C}$ under $0.15 \mathrm{mPa}$ high pressure. The optimum steaming time should be 60 to $90 \mathrm{~min}$, where toxicity and efficacy could remain balance [105]. They are capable to reduce most of the toxic compounds to less toxic ones, which is the most effective way to make the drug safe to use [106]. The total alkaloids amount and thus the function of the herb do not reduce much. This method is fast and clean, while easy to monitor the quality, as well as cost-effective. It is most commonly used to prepare Chuanwu nowadays [107].

It is always crucial to know how a drug or compound being digested and taken into action inside our body. It is also important to keep track of the fate of the substances, pharmacokinetics is the study of this. As a toxic herbal drug, we must learn how efficient our bodies can eliminate the harmful compounds before the drug can be safely used and prescribed. Using the method of ultra-performance liquid chromatography-tandem mass spectrometry (UPLC-MS/MS) [108, 109] or liquid chromatography-electrospray ionization-tandem mass spectrometry (LC-ESI-MS/MS), the alkaloids residue from the drug in the blood serum could be detected and measured fast and accurately.

\section{Clinical management of Aconitum-poisoned cases}

As mentioned previously, Aconitum poisoning is a serious issue. The consequences are huge for patients suffering from poisons such as AC. This occurs usually by 
accidentally ingest the wild plant, or unprocessed Aconitum, or wrong prescription given by physicians. Lives are threatened because the DDAs are toxic to the heart, neural and gastrointestinal system. When cardiovascular function collapse, the patients are in danger [110].

When the patients suffer from tachyarrhythmia, they would feel dizzy and palpitations occur. It could result in cardiac arrest or myocardial infarction. A 61-year-old man was observed with the above symptoms [111]. The patient was having back pain in the previous 3 months and got prescribed Chinese herbal medicine as analgesics. After consuming a portion of the drug for $1 \mathrm{~h}$, he suffered a lot and admitted to the hospital. He had hypotension, with tachycardia. Lidocaine $100 \mathrm{mg}$ was given immediately, and then with continuous infusion. However, the situation did not improve, and further amiodarone was infused additionally for $36 \mathrm{~h}$. The arrhythmia problem was alleviated and later recovered without other consequences. This was an essential case to prove the usefulness of amiodarone in treating aconitine poisoning induced ventricular tachyarrhythmia. As there is no direct antidote to aconitine poisoning, essential vital support and treatment must be given accurately and effectively. Some other clinical evidence also proved the effect of Flecainide, another antiarrhythmic agent, on treating aconitine poisoning induced ventricular tachyarrhythmia [111].

Another worth mentioning case study was a Caowu poisoning that happened on a 48-year-old Chinese man [112]. He consumed some herbal medicinal wine before admitting to the hospital accident and emergency department. He felt chest pain, numbness all over the body, and then dyspnea. Apart from the typical cardiac toxicity, the patient suffered from polycystic renal haemorrhaging as well, due to a family history of kidney disease. The patient was given acticarbon, atropine and intravenous injected lidocaine. The injection lasted for almost $5 \mathrm{~h}$ but the prognosis was still poor. Hemoperfusion was carried out instead. The heparin level was lowered to none and half in the two perfusion device respectively. Methylepinephrine was given to maintain blood pressure. The arrhythmia improved around $2 \mathrm{~h}$ later, but ventricular bigeminy remained. On the third day after admission to the hospital, the kidney haemorrhage was finally under control. He left the hospital 1 week later. This case emphasizes how important supportive therapy is when dealing with poisoning cases. Blood purification removes the aconitine from the body, and help retaining normal cardiac function. It can also sensitize the heart to antiarrhythmic drugs [77].

A 92-year-old woman took a herbal decoction containing Fuzi to treat her mood swings and maintain health, and was soon appeared to be life-threatening with bradycardia and hypotension after $1 \mathrm{~h}$ [113]. ECG showed ventricular abnormalities, including sinus bradycardia and low-P wave. The patient was treated with an infusion of saline and inotropic agents for one day, and those symptoms were alleviated and the condition backed to normal. The key to saving patients from aconite poisoning is to find out the poisoned substance as soon as possible, and prescribe with appropriate alleviating agents.

\section{Discussion}

In the past, the ancient Chinese wrote the materia medica by trial-and-error. They recorded the usage and pharmacological safe amount and level by experience and tested for the herb-herb combinations one by one until a typical formulation could be concluded. They passed down the methods of processing through generations and improved by years. Case of Aconitum poisoning was reported in the modern era as early as 1867 and onwards the toxicity of Aconitum has caught more and more attention besides its documented therapeutic effects. A recent study that reviewed 40 cases reporting Aconitum poisoning in mainland China from 2004 to 2015 suggested that a majority of the cases appears in persons who believed the medicinally beneficial effect of Aconitum in its toxic form [50]. The dosing issue that brings attention to the therapeutic index of Aconitum between its pharmacological and toxic limits is therefore critical to the safe use of the herb in clinical practice. A local review from the Hospital Authority of Hong Kong on 52 cases of Aconitum poisoning from 2004 to 2009 suggested that overdosing is the major underlying cause of poisoning [114]. There were five recent cases of aconite poisoning from 2016 to 2017, that the patients received medication from the Chinese Medicine Centre of Hospital Authority [115]. They were dispensed with normal doses of processed Fuzi but appeared to have symptoms from mild numbness to hypotension. Two of them exhibited bradycardia and were attended in the intensive care unit. They recovered fully after treatment. A report in 2006 recorded the situation that there were 10 cases of aconite poisoning from 2004 to 2006, however, four of them were not prescribed Aconitum herbs in the formulation [116]. This is a problem that we must face if there was contamination happened in the herbal medicine, or the quality control failure. In the view of safety control, developing a strict quality control with an indicated range of certain substance in Aconitum may be optimal, however, due to the inconsistency of chemical composition between batches and the narrow therapeutic index, the optimal safe range of Aconitum substances may be too narrow to be practical. On the contrary, with the aid of modern science, the functions and properties of an herbal drug could be 
explained and proved by extracts or isolating single compounds. Developing safer methods to detoxify the herbal drugs and enhance drug efficacy in the meantime are beneficial to the society.

Technological advancement has different views on processing methods. The recent studies showed that Fuzi processed without soaking in saline have better medicinal effects while keeping the safety level $[103,104]$. This is inconsistent with ancient wisdom but could be explained by a few reasons. The safety could not be easily monitored by simple baking of crude herb, as the temperature and condition may not be maintained well in the past. Also, the high salt content in herbal medicine helps increase the storage time of the drug. Finally, the quality check of the drug may be easier, as the appearance of the processed drug would be completely different. The Pharmacopoeia should consider introducing or replacing the current method of Fuzi processing since the technology level of the pharmaceutical industries has improved a lot.

A single herb could be either an advantageous drug, or a lethal poison at different doses and forms, so it is essential to determine the optimum dosage for a specific disease or case. Traditional Chinese Medicine is inherited for thousands of years, and modern sciences minimize the risk when using herbal medicine. Both are indispensable in the development of pharmacy; the traditional wisdom provides hints and directions to drug development, while modern medicine brings the knowledge to the next level. Herbal-herbal combination to reduce toxicity could be a good point to research deeper into because it requires no additional treatment on a single drug. For example, the alkaloid in Fangji (Stephania tetrandra) could inhibit the movement of calcium ions crossing the L-type calcium channel, which in turn lower the toxic effect causing arrhythmic of aconite alkaloids [117]. The addition of the combination is an alternative way to detoxify and increase the safety of toxic herbal drugs, and this is valuable in pharmacological development. On the other hand, different ratios of combination with other drugs could result in different toxicity on Aconitum herbs. The five herbs in the " 18 incompatible medicaments" were claimed not to be used together with Aconitum. However, recent studies reviewed that when combining with different ratios, the toxicity of the combination may not increase [118]. More scientific researches on the topic are needed to illustrate the mechanism of herb-herb combination effects on toxic drugs, not only for Aconitum.

\section{Conclusion}

In this review, we update the knowledge advancement about the toxicity and toxicology of Aconitum drugs. The drug has been widely used in ethnomedicine especially in
China despite its toxicity. It has anti-inflammation, antiarrhythmic, analgesic and some other effects as a medicine. Increasing evidence has shown the benefits of using Aconitum herbs in treatment. However, the risk of cardiotoxicity causing arrhythmic, gastrointestinal upset, or even tetraplegia and death is a serious concern. The poisoned cases were usually caused by inappropriate usage, overdose, long term consumption, or herbal drug of poor quality. Cases are studied and the prescription of western antiarrhythmic drugs such as amiodarone or atropine is an immediate response to save lives. Furthermore, the current methods of Aconitum processing are discussed and reviewed. It is concluded that the standard processing method written in the China Pharmacopoeia may not be the best one in terms of enhancing the medicinal effect of the drug, and more researches should be done on reflecting the effectiveness. With the correct ratio to combine Aconitum with other herbal drugs, such as Ginseng, Gancao, Ganjiang and Dahuang, toxicity could be reduced and therapeutic effects could be enhanced.

\begin{abstract}
Acknowledgements
Not applicable

Authors' contributions

YTC and NW wrote the manuscript; YF designed, revised and finalized the manuscript. All authors commented on the manuscript during the writing process. All authors read and approved the final manuscript.

\section{Funding}

This research was funded by the Research Council of the University of Hong Kong (project codes: 104003422, 104004092 and 104004460), Wong's donation (project code: 200006276), a donation from the Gaia Family Trust of New Zealand (project code: 200007008), a contract research project (project code: 260007482), and the Research Grants Committee (RGC) of Hong Kong, HKSAR (Project Codes: 740608, 766211 and 17152116).
\end{abstract}

Availability of data and materials

Not applicable.

\section{Declarations}

Ethics approval and consent to participate

Not applicable.

Consent for publication

Not applicable.

Competing interests

The authors declare that they have no competing interests.

Received: 23 April 2021 Accepted: 16 July 2021

Published online: 27 July 2021

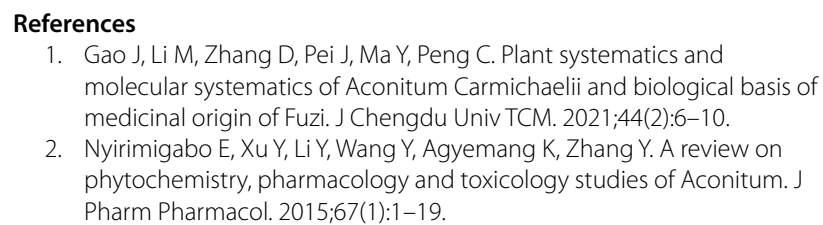


3. Liu S, Li F, LiY, LiW, Xu J, Du H. A review of traditional and current methods used to potentially reduce toxicity of Aconitum roots in Traditional Chinese Medicine. J Ethnopharmacol. 2017;207:237-50.

4. Chan TYK. Incidence and causes of Aconitum alkaloid poisoning in Hong Kong from 1989 to 2010. Phytother Res. 2015;29(8):1107-11.

5. Jaiswal YN, Liang ZT, Ho A, Wong LL, Yong P, Chen HB, et al. Distribution of toxic alkaloids in tissues from three herbal medicine Aconitum species using laser micro-dissection, UHPLC-QTOF MS and LC-MS/MS techniques. Phytochemistry. 2014;107:155-74.

6. Li M, He J, Jiang LL, Ng ESK, Wang H, Lam FFY, et al. The anti-arthritic effects of Aconitum vilmorinianum, a folk herbal medicine in Southwestern China. J Ethnopharmacol. 2013;147(1):122-7.

7. Wagner H, Bauer R, Melchart D, Xiao P-G, Staudinger A. Radix Aconiti Lateral is praeparata Fuzi Radix Aconiti Kusnezoffii praeparata Zhicaowu. In: Chromatographic Fingerprint Analysis of Herbal Medicines. edn.: Springer; 2011: 977-89.

8. Luo Y, Wang C-Z, Sawadogo R, Tan T, Yuan C-S. Effects of herbal medicines on pain management. Am J Chin Med. 2020;48(01):1-16.

9. Min Z. The comparative studies between Chinese medicine and western medicines (Zhongxi Bijiao Yiyaoxue Gailun). Beijing: Higher Education Press; 2006. p. 75-90.

10. Yang M, Ji X, Zuo Z. Relationships between the toxicities of radix Aconiti Lateralis Preparata (Fuzi) and the toxicokinetics of its main diesterditerpenoid alkaloids. Toxins. 2018:10(10):391.

11. Can E, Cheng MZ. Sweating method in Shang Han Lun. J Assoc Tradit Chin Med. 2010;17(1):4-9.

12. Sun Z, Zhao Y, Wang J, Zhang L, Wei S, Jiang F, et al. Research on Fuzi based on animal thermotropism behavior to discover if it has fewer "hot" characteristics without Ganjiang. J Tradit Chin Med. 2012;32(2):208-14.

13. Kang YX, Luczaj $\sqcup$, Ye S. The highly toxic Aconitum carmichaelii Debeaux as a root vegetable in the Qinling Mountains (Shaanxi, China). Genet Resour Crop Evol. 2012;59(7):1569-75.

14. Vaidya AD, Devasagayam TP. Current status of herbal drugs in India: an overview. J Clin Biochem Nutr. 2007;41 (1):1-11.

15. Gogtay NJ, Bhatt HA, Dalvi SS, Kshirsagar NA. The use and safety of nonallopathic Indian medicines. Drug Saf. 2002;25(14):1005-19.

16. Jaiswal Y, Liang Z, Ho A, Wong L, Yong P, Chen H, et al. Distribution of toxic alkaloids in tissues from three herbal medicine Aconitum species using laser micro-dissection, UHPLC-QTOF MS and LC-MS/MS techniques. Phytochemistry. 2014;107:155-74.

17. Wang R, Wang Q. Research progress in the chemical constituents, pharmacological effects and history of Aconiti Radix processing. Cent South Pharm. 2021;19(5):915-20.

18. Matsuyama S, Taniguchi M, Tsukioka J, Goto K, Nishi K. Genus identification of toxic plant by DNA. Forensic Sci Int Genet Suppl Ser. 2009;2(1):308-9.

19. Commission CP. Pharmacopoeia of the People's Republic of China, Part I. Beijing: China Medical Science Press; 2020.

20. Pharmacopoeia Commission C. Pharmacopoeia of the People's Republic of China, vol. 1. Beijing: Chinese Medical Science and Technology Press; 2010

21. Zhu JQ, Kang LY, Ye QF, Fan GW, Liang YB, Yan C, et al. Effects of Shenfu injection and its main components on the contraction of isolated rat thoracic aortic rings. Plos ONE. 2013;8(10):e78026.

22. Liu XX, Jian XX, Cai XF, Chao RB, Chen QH, Chen DL, et al. Cardioactive C-19-diterpenoid alkaloids from the lateral roots of Aconitum carmichaeli "Fu Zi." Chem Pharm Bull. 2012;60(1):144-9.

23. Dunn J, Grider MH. Physiology, Adenosine Triphosphate (ATP). 2020.

24. Kim TT, Dyck JR. Is AMPK the savior of the failing heart? Trends Endocrinol Metab. 2015;26(1):40-8.

25. Ameri A. Effects of the alkaloids 6-benzoylheteratisine and heteratisine on neuronal activity in rat hippocampal slices. Neuropharmacology. 1997;36(8):1039-46.

26. Heubach JF, Schule A. Cardiac effects of lappaconitine and N-deacetyllappaconitine, two diterpenoid alkaloids from plants of the Aconitum and Delphinium species. Planta Med. 1998;64(1):22-6.

27. Wen-Ting S, Fa-Feng C, Li X, Cheng-Ren L, Jian-Xun L. Chinese medicine shenfu injection for heart failure: a systematic review and meta-analysis. Evid Based Complement Altern Med. 2012;2012:713149.
28. Chen G. Effects of Shenfu injection on chemotherapy-induced adverse effects and quality of life in patients with advanced nonsmall cell lung cancer: a systematic review and meta-analysis. J Canc Res Ther. 2018;14:S549-55.

29. Jin YY, Gao H, Zhang XY, Ai H, Zhu XL, Wang J. Shenfu Injection (sic) inhibits inflammation in patients with acute myocardial infarction complicated by cardiac shock. Chin J Integr Med. 2017;23(3):170-5.

30. Tong PJ, Wu CL, Wang XF, Hu HZ, Jin HT, Li CY, et al. Development and assessment of a complete-detoxication strategy for Fuzi (lateral root of Aconitum carmichaeli) and its application in rheumatoid arthritis therapy. J Ethnopharmacol. 2013;146(2):562-71.

31. Bello-Ramirez AM, Buendia-Orozco J, Nava-Ocampo AA. A QSAR analysis to explain the analgesic properties of Aconitum alkaloids. Fundam Clin Pharmacol. 2003;17(5):575-80.

32. Taki M, Niitu K, Omiya Y, Noguchi M, Fukuchi M, Aburada M, et al. 8-O-cinnamoylneoline, a new alkaloid from the flower buds of Aconitum carmichaeli and its toxic and analgesic activities. Planta Med. 2003;69(9):800-3.

33. Mori T, Murayama M, Bando H, Kawahara N. Studies on the constituents of Aconitum species. XII. Syntheses of jesaconitine derivatives and their analgesic and toxic activities. Chem Pharm Bull. 1991;39(2):379-83.

34. Gutser UT, Friese J, Heubach JF, Matthiesen T, Selve N, Wilffert B, et al. Mode of antinociceptive and toxic action of alkaloids of Aconitum spec. Naunyn-Schmiedebergs Arch Pharmacol. 1998;357(1):39-48.

35. Nie JH, Wang F, Ji TF, Zhao J, Zhao FC. Assessment of in vitro cardiotoxicity of extract fractions and diterpene alkaloids from Aconitum leucostomum Worosch: a short communication. J Pharm Biomed Anal. 2017;137:84-9.

36. Cheng H-L, Wang F-L, Zhao Y-G, Zhang Y, Jin M-C, Zhu Y. Simultaneous determination of fifteen toxic alkaloids in meat dishes and vegetable dishes using double layer pipette tip magnetic dispersive solid phase extraction followed by UFLC-MS/MS. Anal Methods. 2018;10(10):1151-62.

37. Ono M, Satoh T. Pharmacological studies of lappaconitine. Analgesic activities. Arzneimittel-Forschung. 1988;38(7):892-5.

38. Li Y, Zheng Y, Yu Y, Gan Y, Gao Z. Inhibitory effects of lappaconitine on the neuronal isoforms of voltage-gated sodium channels. Acta Pharmacol Sinica. 2018;1:451-9.

39. Liang $\mathrm{S}$, Tan X, Gao J, Hu Y, Wang W. Study on acute toxicity of total alkaloids of processed Radix Aconiti Lateralis and its effects on blood histamine contents and pathomorphological changes in nasal mucosa in allergic rhinitis guinea pigs, China. J Tradit Chin Med Pharm. 2011;26(12):2986-9.

40. Lai MC, Liu IM, Liou SS, Chang YS. Mesaconitine plays the major role in the antinociceptive and anti-inflammatory activities of radix Aconiti carmichaeli (Chuan Wu). J Food Drug Anal. 2011;19(3):362-8.

41. Zhang C. Zhongyi Huoshengpai Tantao (Research on Divine-Fire Medical School in TCM). Beijing: People's Medical Publishing House; 2007. p. 57-112.

42. Xiao K, Wang L, Liu YQ, Peng C, Yan GY, Zhang JJ, et al. Study of aconitine toxicity in rat embryos in vitro. Birth Defects Res Part B-Dev Reprod Toxicol. 2007:80(3):208-12.

43. Wu J, Guo Z, Zhu Y, Huang Z, Gong X, Li Y, et al. A systematic review of pharmacokinetic studies on herbal drug Fuzi: Implications for Fuzi as personalized medicine. Phytomedicine. 2018;44:187-203.

44. Ameri A. The effects of Aconitum alkaloids on the central nervous system. Prog Neurobiol. 1998;56(2):211-35.

45. Fu X, Lu R, Zhao S. Simultaneous quantitation of six aconitum alkaloids and three flavonoids in the herb couple of radix aconiti lateralisradix glycyrrhizae (Fuzi-Gancao) by UHPLC-ESI-MS/MS. Pharmacogn Mag. 2017;13(51):425.

46. Yue H, Pi Z, Song F, Liu Z, Cai Z, Liu S. Studies on the aconitine-type alkaloids in the roots of Aconitum carmichaeli Debx by HPLC/ESIMS/ MSn. Talanta. 2009;77(5):1800-7.

47. Jian X-X, Tang P, Liu X-X, Chao R-B, Chen Q-H, She X-K, et al. Structurecardiac activity relationship of C19-diterpenoid alkaloids. Nat Prod Commun. 2012;7(6):713-20.

48. Chan TYK. Aconitum alkaloid content and the high toxicity of aconite tincture. Forensic Sci Int. 2012;222(1-3):1-3. 
49. Strzelecki A, Pichon N, Gaulier JM, Amiel JB, Champy P, Clavel M. Acute toxic herbal intake in a suicide attempt and fatal refractory ventricular arrhythmia. Basic Clin Pharmacol Toxicol. 2010;107(2):698-9.

50. Li H, Liu L, Zhu S, Liu Q. Case reports of aconite poisoning in mainland China from 2004 to 2015: a retrospective analysis. J Forensic Leg Med. 2016;42:68-73.

51. Benn M. The toxicology and pharmacology of diterpenoid alkaloids. Alkaloids. 1983;1:153-210.

52. Pullela R, Young L, Gallagher B, Avis SP, Randell EW. A case of fatal aconitine poisoning by monkshood ingestion. J Forensic Sci. 2008;53(2):491-4

53. Singhuber J, Zhu M, Prinz S, Kopp B. Aconitum in Traditional Chinese Medicine-A valuable drug or an unpredictable risk? J Ethnopharmacol. 2009;126(1):18-30.

54. Fu M, Wu M, Qiao Y, Wang Z. Toxicological mechanisms of Aconitum alkaloids. Pharmazie. 2006;61(9):735-41.

55. Ameri A, Simmet T. Interaction of the structurally related Aconitum alkaloids, aconitine and 6-benzyolheteratisine, in the rat hippocampus. Eur J Pharmacol. 1999;386(2-3):187-94.

56. Schmidt $H$, Schmitt $O$. Effect of aconitine on the sodium permeability of the node of Ranvier. Pflugers Arch. 1974;349(2):133-48.

57. Merchant HC, Choksi ND, Ramamoorthy K, Parihar LM, Shikaripurkar NK. Aconite poisoning and cardiac arrhythmias: report of 3 cases. Indian J Med Sci. 1963;17:857-65.

58. Sheikh-Zade YR, Cherednik IL, Galenko-Yaroshevskii PA. Peculiarities of cardiotropic effect of aconitine. Bull Exp Biol Med. 2000;129(4):365-6.

59. Li M, Xie X, Chen $\mathrm{H}$, Xiong $\mathrm{Q}$, Tong $\mathrm{R}$, Peng $\mathrm{C}$, et al. Aconitine induces cardiotoxicity through regulation of calcium signaling pathway in zebrafish embryos and in H9c2 cells. J Appl Toxicol. 2020;40(6):780-93.

60. Chan TYK. Aconite poisoning presenting as hypotension and bradycardia. Hum Exp Toxicol. 2009:28(12):795-7.

61. Alalmay A, Al Bashabshe A, Al Shamrani N, Othman LB, Alfaifi M, Algarni $Y$, et al. Aconite poisoning with good outcome, case study and literature review. Case Rep Clin Med. 2020;9(08):217.

62. Yamanaka H, Doi A, Ishibashi H, Akaike N. Aconitine facilitates spontaneous transmitter release at rat ventromedial hypothalamic neurons. $\mathrm{Br}$ J Pharmacol. 2002;135(3):816-22.

63. Jian S, Liu X, Zhang Y. Advances in research on cardiovascular toxicity of Radix Aconiti. Chin J Modern Appl Pharm. 2019;36(14):1850-5

64. Hirasawa M, Nishihara M, Takahashi M. Activity of ventromedial hypothalamic neurons suppressing heart rate is associated with paradoxical sleep in the rat. Brain Res. 1998;797(1):103-8.

65. Lu HR, De Clerck F. R 56 865, a Na+/Ca(2+)-overload inhibitor, protects against aconitine-induced cardiac arrhythmias in vivo. J Cardiovasc Pharmacol. 1993;22(1):120-5.

66. Yang L, Chen Y, Zhou J, Sun J, Jiang W, Liu T, et al. Aconitine induces mitochondrial energy metabolism dysfunction through inhibition of AMPK signaling and interference with mitochondrial dynamics in $\mathrm{SH}$ SY5Y cells. Toxicol Lett. 2021:347:36-44.

67. Ameri A. Inhibition of rat hippocampal excitability by the Aconitum alkaloid, 1-benzoylnapelline, but not by napelline. Eur J Pharmacol. 1997;335(2-3):145-52

68. Singh M, Routledge PA. Poisoning by toxic plants and fungi. Medicine. 2020;48(3):218-9.

69. Sato H, Yamada C, Konno C, Ohizumi Y, Endo K, Hikino H. Pharmacological actions of aconitine alkaloids. Tohoku J Exp Med. 1979;128(2):175-87.

70. Hofmann V, Landmann A, Schmitt G, Krauskopf A, Bartel M. A fatal case of aconite poisoning: accidental intake of a monkshood extract. Forensic Toxicol. 2020;38(2):511-6.

71. Chan TYK, Tomlinson B, Critchley J. Aconitine poisoning following the ingestion of Chinese herbal medicines: a report of eight cases. Aust N Z J Med. 1993;23(3):268-71.

72. Tshering U, LeVine S, Watts M. Hypotension, bradycardia and reversible conduction defect induced by prescription of Bhutanese traditional medicines. Bhutan Health J. 2018:4(2):43-5.

73. Chan TYK, Tomlinson B, Critchley J, Cockram CS. Herb-induced aconitine poisoning presenting as tetraplegia. Vet Hum Toxicol. 1994:36(2):133-4
74. Chandurkar M, Patrike G, Chauhan N, Mulay S, Vethekar M, Akhtar J, et al. A case report of cardiotoxicity due to homeopathic drug overdose. Int J Med Res Health Scie. 2014:3(4):1072-5.

75. Dwivedi S, Aggarwal A, Sharma V. Cardiotoxicity from "safe" herbomineral formulations. Trop Doct. 2011:41(2):113-5.

76. Chan $\mathrm{CP}, \mathrm{Au} \mathrm{CKH}$. Three cases of aconite root poisoning due to Bikhama in a Hong Kong Nepalese family. Hong Kong J Emerg Med. 2010;17(2):158-62.

77. Lin CC, Chan TYK, Deng JF. Clinical features and management of herbinduced aconitine poisoning. Ann Emerg Med. 2004;43(5):574-9.

78. Bonanno G, Ippolito M, Moscarelli A, Misseri G, Caradonna R, Accurso $\mathrm{G}$, et al. Accidental poisoning with Aconitum: case report and review of the literature. Clin Case Rep. 2020;8(4):696-8.

79. Yang L, Wang Y, Xu H, Huang G, Zhang Z, Ma Z, et al. Panax ginseng inhibits metabolism of diester alkaloids by downregulating CYP3A4 enzyme activity via the pregnane $\mathrm{X}$ receptor. Evid Based Complement Altern Med. 2019;2019:3508658

80. Yang L, Wang Y, Huang G, Li J, Zhang Z, Ma Z, et al. Simultaneous evaluation of the influence of Panax ginseng on the pharmacokinetics of three diester alkaloids after oral administration of aconiti lateralis radix in rats using UHPLC/QQQ-MS/MS. Evid Based Complement Altern Med. 2018;2018:6527549

81. Wang X, Li L, Li Y, Li C, Zhang D. Toxicity-reducing effect of compatibility of Aconiti Lateralisradix praeparata with different proportion of Panax Ginseng in neonatal rat cardiomyocytes. Chin J Exp Tradit Med Formulae. 2015;21:153-8.

82. Sun J, Zhang G, Su P. Effects of ginseng aconite and its effective components combination on the mRNA's expression of oxidase CYP2J3 hydroxylase, CYP4A3 and CYP4F11. Chin J New Drugs. 2019;28:2081-8.

83. Sun J, Li H, Zhang G, Su P, Ma M, Yang H, et al. Combination of ginseng, roasted liquorice and radix aconiti chamichaeli and their effect on the mice acute toxicity. Pharmacol Clin Chin Materia Medica. 2019;35(2):96-101.

84. He Y, Wei Z, Ci X, Xie Y, Yi X, Zeng Y, et al. Effects of liquorice on pharmacokinetics of aconitine in rats. Xenobiotica. 2019;49(12):1485-93.

85. Liu Q, Zhang Y, Wan H, Yang J, Zhou T. Detoxicated effect of compatibility of hypaconitine and liquiritin, glycyrrhetinic acid. China J Tradit Chin Med Pharm. 2013;28(9):2601-4.

86. Wang L, Zhang Y, He Y, Wan H, Zhou H, Yang J. Effect of different compatibility proportion of active constituent of Fuzi (Radix Aconiti Carmichaeli) and Gancao (Glycyrrhiza Uralensis) on H9c2 myocardial cell with oxygen-glucose deprivation. J Tradit Chin Med. 2016:57:1327-31.

87. Yan P, Mao W, Jin L, Fang M, Liu X, Lang J, et al. Crude Radix Aconiti Lateralis Preparata (Fuzi) with glycyrrhiza reduces inflammation and ventricular remodeling in mice through the TLR4/NF-kB Pathway. Mediat Inflamm. 2020;2020:5270508.

88. Lu X, Zhang L, Li P, Wang J, Li R, Huang Y, et al. The protective effects of compatibility of Aconiti Lateralis Radix Praeparata and Zingiberis Rhizoma on rats with heart failure by enhancing mitochondrial biogenesis via Sirt1/PGC-1a pathway. Biomed Pharmacother. 2017;92:651-60.

89. GENG S, GE H,WANG X. Antioxidant Effect of Aconite and Compatibility of Aconite dried and Ginger on Neonatal Rats' Myocardial Cells induced by H_2O_2. Journal of Emergency in Traditional Chinese Medicine 2014:11.

90. Wen J, Wang J, Zhang L, Lu X, Wei S, Li H, et al. Research progress of the pharmacologic effects and mechanism of Aconiti Latetralis Radix Praeparata compatible with Zingiberis Rhizome in the treatment of heart failure. Evaluat Anal Drug Use Hosp China. 2019;19(10):1167-70.

91. Jiajia L, Lina Y, Weihua Z, Lili Z, Yanan L, Sa Z, et al. Study on Content Change of Ester Alkaloids in Aconite Processing and Compatibility with Chinese Rhubarb. World Sci Technol Modern Tradit Chin Med Materia Medica. 2014;16(1):38-44.

92. Gao P, Ye Z. Experimental Study on Effects of Radix et Rhizome Rhei on Toxicity and Efficacy of Radix Aconiti in Compatibility. Traditional Chinese Drug Research \& Clinical Pharmacology. 2014;25(5):542-6.

93. Li Y, Ju L, Deng H, Zhang Z, Wang L, Hou Z, et al. Research methods of "18 incompatible medicaments" incompatibility toxicity characterization of traditional Chinese medicine based on early evaluation of overall toxicity. Chin J Pharmacol Toxicol. 2015;29(6):960-6. 
94. Hao DC, Ge GB, Xiao PG, Wang P, Yang L. Drug Metabolism and Pharmacokinetic Diversity of Ranunculaceae Medicinal Compounds. Curr Drug Metab. 2015;16(4):294-321.

95. Song S, Tang QF, Huo HL, Li HC, Xing XF, Luo JB. Simultaneous quantification and pharmacokinetics of alkaloids in herba ephedrae-Radix Aconiti lateralis extracts. J Anal Toxicol. 2015;39(1):58-68.

96. Zhu LJ, Wu JJ, Zhao M, Song WJ, Qi XX, Wang YR, et al. Mdr1 a plays a crucial role in regulating the analgesic effect and toxicity of aconitine by altering its pharmacokinetic characteristics. Toxicol Appl Pharmacol. 2017:320:32-9.

97. Yang CP, Zhang TH, Li Z, Xu L, Liu F, Ruan JX, et al. P-glycoprotein is responsible for the poor intestinal absorption and low toxicity of oral aconitine: In vitro, in situ, in vivo and in silico studies. Toxicol Appl Pharmacol. 2013;273(3):561-8.

98. Calixto J. Efficacy, safety, quality control, marketing and regulatory quidelines for herbal medicines (phytotherapeutic agents). Braz J Med Biol Res. 2000;33(2):179-89.

99. Liang Y-Z, Xie P, Chan K. Quality control of herbal medicines. J Chromatogr B. 2004;812(1-2):53-70.

100. Kasahara Y, Kumaki K, Katagiri S. Identification and determination of food poisoning components contained in Aconitum roots and their toxicity to mice. J Food Hyg Soc Jpn. 1996;37(4):202-9.

101. Kasahara Y, Itou T, Numazawa T, Wada A. Aconitine analogues in wild Aconitum plants: contents toxicity to mice and decrease by boiling. Food Hyg Saf Sci. 2013;54(5):364-9.

102. Liu M, Cao Y, Lv DY, Zhang W, Zhu ZY, Zhang H, et al. Effect of processing on the alkaloids in Aconitum tubers by HPLC-TOF/MS. J Pharm Anal. 2017;7(3):170-5.

103. Wen R, Li D, Zhao X, Wang J, Zhao Y, Zhang P, et al. Rationality of the processing methods of aconiti lateralis radix (Fuzi) based on chemical analysis. Acta pharmaceutica Sinica. 2013:48(2):286-90.

104. Peng S, Zhang X, Yuan J, Zhang Y, Wang X, Sun M, et al. A Comparative study on 4 kinds of processing methods of Paofuzi based on Zhang Zhongjing's academic thoughts. Modern Tradit Chin Med Mater Med World Sci Technol. 2018;20(5):716-21.

105. Liu F, Yu X, Li F, Tan Y, Qiao Y. Determination of three kind of diester diterpenoid alkaloids (DDAs) in Aconitum carmichaeli and its processed products by HPLC. China J Chi Mate Med. 2006:31(14):1160-2.

106. Yang L, Chen Y, Liu Q, Li F. Comparative studies on acute toxicity and pharmacodynamics of Aconitum carmichaeli. Beijing Zhongyiyao Duxue Xuebao. 1997;2:20-1

107. Wang JS, van der Heijden R, Spruit S, Hankermeier T, Chan K, van der Greef J, et al. Quality and safety of Chinese herbal medicines guided by a systems biology perspective. J Ethnopharmacol. 2009;126(1):31-41.

108. Yu B, Cao Y, Xiong YK. Pharmacokinetics of aconitine-type alkaloids after oral administration of Fuzi (Aconiti Lateralis Radix Praeparata) in rats with chronic heart failure by microdialysis and ultra-high performance liquid chromatography-tandem mass spectrometry. J Ethnopharmacol. 2015;165:173-9.

109. El-Shazly M, Tai CJ, Wu TY, Csupor D, Hohmann J, Chang FR, et al. Use, history, and liquid chromatography/mass spectrometry chemical analysis of Aconitum. J Food Drug Anal. 2016;24(1):29-45.

110. Wu P. Experience intreatment of 20 cases of acute aconite poisoning. Jilin Med J. 2012;33:1942-3.

111. Yeih D-F, Chiang F, Huang S-KS. Successful treatment of aconitine induced life threatening ventricular tachyarrhythmia with amiodarone. Heart. 2000;84(4):e8.

112. Chen XG, Wu RK, Jin HZ, Gao RX, Yang BH, Wang Q. Successful Rescue of a Patient with Acute Aconitine Poisoning Complicated by Polycystic Renal Hemorrhage. J Nippon Med Sch. 2015;82(5):257-61.

113. Chou P-Y, Wang C-C, Tai C-J, Yang T-L, Tang Y-J. Bradycardia and hypotension from improper use of aconite root: a case report and brief review. Complement Med Res. 2018;25(5):338-43.
114. Chen SP, Ng SW, Poon WT, Lai CK, Ngan TM, Tse ML, et al. Aconite poisoning over 5 years: a case series in Hong Kong and lessons towards herbal safety. Drug Saf. 2012;35(7):575-87.

115. Lau KK, Chow TYA, Chan CK, Chan YC, Ng CHV, Ng SH, et al. Hong Kong Poison Information Centre: Annual report 2017. Hong Kong J Emerg Med. 2018;25(6):313-23.

116. Poon WT, Lai CK, Ching CK, Tse KY, So YC, Chan YC, et al. Aconite poisoning in camouflage. Hong Kong Med J. 2006;12(6):456-9.

117. Qiang X, Zhu Z, Jiang L, Cai T. Attenuated way and the efficacy of Fuzi(Aconite). Guiding J Tradit Chin Med Pharm. 2018;24(1):34-6.

118. Zhang T, Zhuang P, Lai X, Lu Z, Li L, Zhang Y. Acute toxicity studies on compatibility of "pinellia, trichosanthes, fritillaria, ampelopsis, bletilla attack aconitum." Chin Tradit Herb Drugs. 2013:44(17):2442-5.

119. Zhang S, Wu J, Jia Z, Sun J. Dose-toxicity relationship study for cardiotonic effect of aconitine. Chinese J Exper Tradit Med Form. 2012; 19063.

120. Fang $\mathrm{K}, \mathrm{Li} Z$ Z, Li G, Shao X. Protection of hypaconitine on $\mathrm{H} 2 \mathrm{O} 2$ induced myocardial apoptosis in rats. Zhongguo Zhong Yi Yao Ke Ji. 2010;17(4):315-318.

121. Soo Y, Jin LY, Jung KH, Kyu KM, Geuk PH, Heun SJ, Sook LH, Ki Y-C, Chang C. Higenamine reduces apoptotic cell death by induction of heme oxygenase-1 in rat myocardial ischemiareperfusion injury. Apoptosis 2006;11(7):1091-1100. https://doi.org/10.1007/s10495-006-7110-y.

122. Gui-bo, Hong S, Xiang-bao S, Jin M, Qiang H, Bo Z, Min L, Hui-bo W, Xiao-bo X, Sun. Aconitine-induced Ca2+ overload causes arrhythmia and triggers apoptosis through p38 MAPK signaling pathway in rats. Toxicol Appl Pharmacol 2014; 279(1):8-22. https://doi.org/10.1016/j. taap.2014.05.005.

123. Wang $P, M a X$, Zhang $H$, Yang $Y$, Yang $Y$, Wang $H$, Lao A. Influnce of lappaconitine on electro cardiogram of anesthetized rats and its antiarrhythmic effect on experimental. Zhongguo Yao Li Xue Tong Bao. 1997:13(3):263.

124. Liu JH, Zhu YX, Tang XC. Anti-inflammatory and analgesic activities of N-deacetyllappaconitine and lappaconitine. Acta Pharmacologica Sinica. 1987;8(4):301-305.

125. Song L, Hong X, Ding X, Zang Z. Modern Dictionary of Chinese Materia Medica. People's Medical Publishing House: Beijing. 2001.

126. Dzhakhangirov F, Sadritinov F. Antiarrhythmic effect of allapanine (lappaconitine hydrobromide). Dokl Acad Nauk UzSSR. 1985;7:46-47.

127. Nanjingzhongyiyaodaxue. Zhongyao Dacidian. Shanghai Kejishu Chubanshe, 2006

128. Murayama M, Mori T, Bando H, Amiya T. Studies on the constituents of Aconitum species. IX. The pharmacological properties of pyro-type aconitine alkaloids components of processed aconite powder 'Kakobushi-matsu': analgesic antiinflammatory and acute toxic activities. J Ethnopharmacol 1991;35(2):159-164. https://doi.org/10.1016/03788741(91)90068-O

129. Friese J, Gleitz Ulrike J, Gutser Jürgen T, Heubach F, Matthiesen T, Wilffert $B$, Selve N. Aconitum sp. alkaloids: the modulation of voltage-dependent $\mathrm{Na}+$ channels toxicity and antinociceptive properties. European J Pharmacol 1997;337(2-3):165-174. https://doi.org/10.1016/500142999(97)01268-5

130. Zhang Q, Chen X, Luo Y, Ren H, Qiao T. Fuzi enhances anti-tumor efficacy of radiotherapy on lung cancer. J Cancer 2017:8(19):3945-3951. https://doi.org/10.7150/jca.22162.

131. Hazawa M, Wada K, Takahashi K, Mori T, Kawahara N, Kashiwakura I. Suppressive effects of novel derivatives prepared from Aconitum alkaloids on tumor growth. Investigational New Drugs 2009;27(2):111-119. https://doi.org/10.1007/s10637-008-9141-4.

\section{Publisher's Note}

Springer Nature remains neutral with regard to jurisdictional claims in published maps and institutional affiliations. 